\title{
LONG-TERM SURVIVAL AFTER RESECTION OF A MEDIASTINAL METASTASIS FROM A RENAL CELL CARCINOMA
}

\author{
Iwao Takanami, MD, Masao Naruke, MD, and Susumu Kodaira, MD, Tokyo, Japan
}

Twenty-five percent to $30 \%$ of patients with a renal cell carcinoma have a metastasis by the time the renal cell carcinoma is diagnosed, and $30 \%$ to $50 \%$ of these patients subsequently have pulmonary metastases. ${ }^{1,2}$ Pulmonary metastases are common in patients with renal cell carcinoma and usually consist of multiple nodules of varying sizes that develop in both lung fields. In contrast, mediastinal adenopathy but no pulmonary parenchymal disease is a rare manifestation of intrathoracic involvement. Herein we describe the case of a patient with a mediastinal metastasis of a renal cell carcinoma. A mediastinal lymph node resection was performed, and 6 years after the operation the patient remains alive.

Clinical summary. Twelve months before admission to our facility, our patient, a 50-year-old man, had undergone a left nephrectomy. He appeared to be doing well after the operation until a routine follow-up chest radiograph revealed a right paratracheal adenopathy (Fig. 1).

From the First Department of Surgery, Teikyo School of Medicine, Tokyo, Japan.

Received for publication Nov. 4, 1997; accepted for publication Dec. 8, 1997.

Address for reprints: Iwao Takanami, MD, First Department of Surgery, Teikyo School of Medicine, 2-11 Kaga 2-Chome, Itabashi-Ku, Tokyo 173, Japan.

J Thorac Cardiovasc Surg 1998;115:1218-9

Copyright (C) 1998 by Mosby, Inc.

$0022-5223 / 98 \$ 5.00+0 \quad \mathbf{1 2 / 5 4 / 8 8 0 0 6}$
Chest computed tomography (CT) showed paratracheal adenopathy (Fig. 2) but no parenchymal metastases. Bronchoscopic examination revealed nothing abnormal and cytologic studies of sputum and bronchial washings revealed no contributory findings. Other tests, which included abdominal CT scans, brain CT scans, gallium scintigraphy, and bone scintigraphy, showed no evidence of any other tumors.

Thus thoracotomy was performed and the mass, located between the trachea and the superior vena cava, was excised. The tumor, measuring $58 \times 55 \times 35 \mathrm{~mm}$, was encapsulated and easily resected, and a subsequent pathologic examination confirmed that it was a metastatic, lymphoid tissue renal cell carcinoma. The patient was given no postoperative therapy and to date, 6 years after the operation, has had no recurrence of tumor.

Comments. Pulmonary metastasis of a renal cell carcinoma itself is an initial feature of the disease in only $2 \%$ of cases and in such cases usually appears as multiple nodules in both lung fields. ${ }^{2}$ Patients with renal cell carcinoma who have no parenchymal abnormalities but do have a hilar or paratracheal adenopathy, indicating intrathoracic involvement of the renal cell carcinoma, are rarely encountered. In a series of 1451 patients, only 75 $(5 \%)$ were found to have a mediastinal adenopathy, whereas more than $90 \%$ had pulmonary parenchymal metastases and no isolated lymph node involvement in the chest cavity. ${ }^{3}$ The 5-year survival of patients with unresected metastatic renal cell carcinoma is only $2.7 \% .^{4}$ As for treatment of patients with metastatic renal cell carci- 


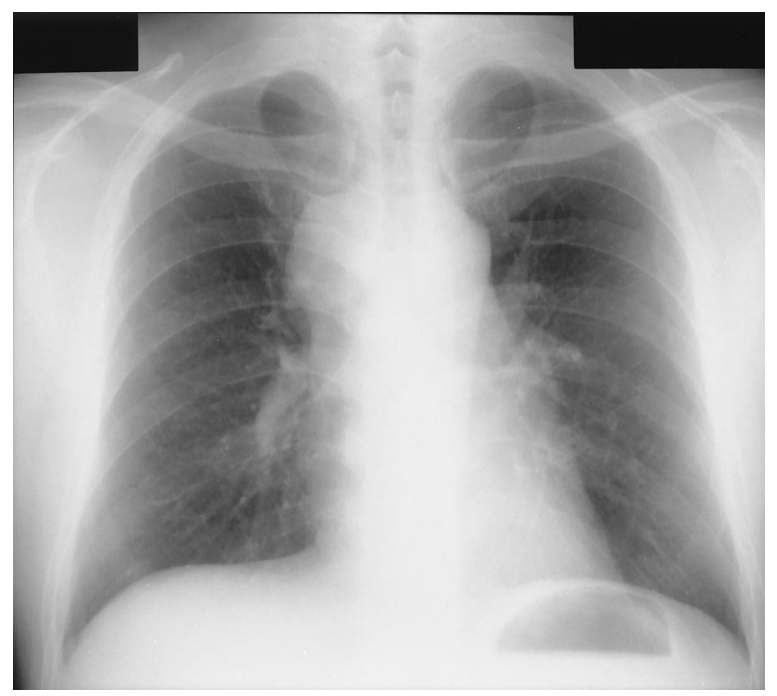

Fig. 1. A well-defined mass in the medistinum.

noma, chemotherapy, radiation therapy, and/or immunotherapy, single or in combination, have not been found to be effective; resective surgery still remains the best procedure for patients with a limited metastatic renal cell carcinoma. Cerfolio and associates ${ }^{5}$ reported that patients treated by resection of a solitary pulmonary metastasis had a 5-year survival of $46 \% .^{5}$ Also, the 5-year survival of 41 patients with renal cell carcinoma undergoing surgical resection of a solitary metastasis in the lung, cranium, abdomen, pelvis, neck, or extremity was found to be $31 \%{ }^{6}$ Although patients having renal cell carcinoma with a lymph node metastasis were not among the 41 just mentioned, these findings indicate that aggressive surgical treatment of isolated metestatic renal cell carcinoma is of benefit. The outcome of mediastinal metastasis not only of renal cell carcinoma but also of infradiphragmatic malignancies is generally poor. So far as we can determine, our patient is the first reported case of long-term survival after

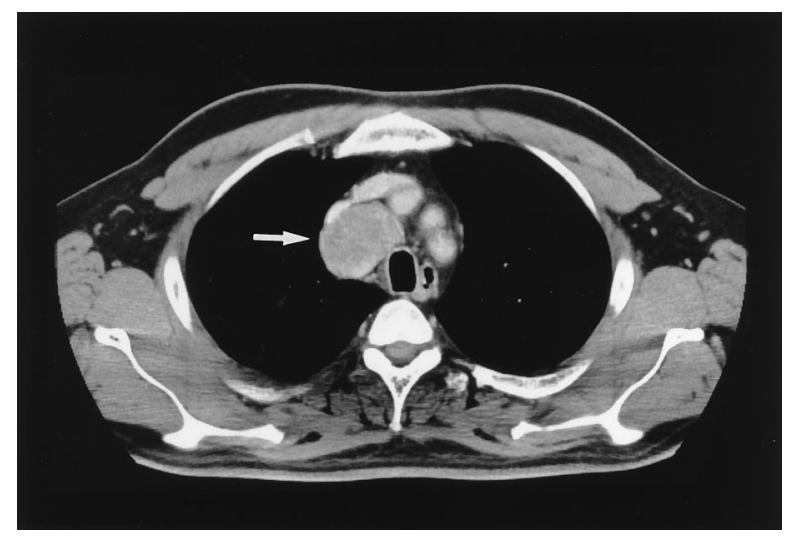

Fig. 2. CT scan shows a mass located between the superior vena cava and the trachea.

resection of solitary mediastinal lymph node metastasis of renal cell carcinoma.

\section{REFERENCES}

1. Dekernion JB, Ramming KP. The natural history of metastatic renal cell carcinoma: a computer analysis. J Urol 1978;120: $148-523$

2. Holland JM. Proceedings: cancer of kidney-natural history and staging. Cancer 1976;32:1030-41.

3. Saitoh H. Distant metastasis of renal adenocarcinoma. Cancer 1981;48:1487-91.

4. Riches E. The natural history of renal tumors. In: Tumors of the kidney and ureter. Edinburgh: Churchill Livingstone; 1984. p. 124-34.

5. Cefolio RJ, Allen MS, Deschamps C, Daly RC, Wallrichs SL, Trastek, et al. Pulmonary resection of metastatic renal cell carcinoma. Ann Thorac Surg 1994;57:339-44.

6. Kierney PC, Heerden JAV, Segura SW, Weaver AL. Surgeon's role in the management of solitary renal cell carcinoma metastases occurring subsequent to initial curative nphrectomy: an institutional review. Ann Surg Onocol 1994;1:345-52. 